\title{
UNA SEGUNDA ESPECIE DE KRUGIODENDRON (RHAMNACEAE) EN EL NEOTRÓPICO
}

\author{
José GonzÁlez Ramírez y y Lus Poveda Álvarez ${ }^{2}$ \\ ${ }^{1}$ Instituto Nacional de Biodiversidad (INB), apdo. 22-3100, Santo Domingo, Heredia, Costa Rica. \\ jgonzal@inbio.ac.cr \\ ${ }^{2}$ Herbario Juvenal Valerio (JVR), Universidad Nacional de Costa Rica, apdo. 86-3000, Heredia, Costa Rica. \\ lpoveda@una.ac.cr
}

\begin{abstract}
Krugiodendron acuminatum, the second species of a previously monospecific genus is described and illustrated, based on material from Costa Rica and Mexico. This new species is immediately distinguished from K. ferreum (Vahl) Urb., by the difference in the apex of the leaf blade; the first (as is implicit in the epithet) has an acuminate apex, while that of second is consistently emarginate.
\end{abstract}

RESUMEN. Se describe e ilustra Krugiodendron acuminatum, la segunda especie de un género previamente monoespecifico, con base en material de Costa Rica y México. Esta nueva especie se destingue inmediatamente de K. ferreum (Vahl) Urb. por la diferencia en el ápice de la lámina foliar; en la primera (como está implicito en el epíteto) el ápice es acuminado, mientras que en la segunda es consistentemente emarginado.

Palabras Clave / Key words: Rhamnaceae, Krugiodendron acuminatum, Costa Rica, México.

Krugiodendron es un género de árboles distribuido desde el sur de Florida (EE.UU.) hasta América Central y las Antillas Mayores (Liogier 1994). Este género fue dedicado a Carl Wilhelm Leopold Krug (1833-1898), autor, junto con Urban, de la Flora de las Indias Occidentales.

Krugiodendron ferreum se ajusta perfectamente a la distribución del género, mientras que $K$. acuminatum sólo se ha recolectado disyuntivamente en México y Costa Rica (González, en preparación). Estas dos especies habitan en este último país de manera alopátrica; la primera crece en bosques secos y húmedos, en las llanuras de Guanacaste y en la cordillera del mismo nombre, mientras que la segunda se halla en bosques muy húmedos estacionales, generalmente costeros, como los del Pacífico Central (en las cercanías del Parque Nacional Manuel Antonio) o los de la Península de Osa (en el Parque Nacional Corcovado).

En la familia Rhamnaceae Krugiodendron es un género distintivo por sus flores apétalas. Entre los géneros con frutos drupáceos, se caracteriza por las semillas carentes de endospermo (Liogier 1994). Dos géneros muy similares (típicos de la flora antillana) tienen flores con pétalos (Auerodendron Urban.) o poseen semillas con el endospermo ruminado (Reynosia Griseb.).
Krugiodendron acuminatum J. A. González \& Poveda, sp. nova

TIPO: Costa Rica. Puntarenas: Aguirre, Quepos, Parque Nacional Manuel Antonio, $09^{\circ} 23^{\prime} 00^{\prime} \mathrm{N}$, 8409'00"W, 1-100 m, 4 mayo 1991 (fl), P. Harmon 219 (holotipo, INB; isotipo, MO).

Arbor vel frutex, 8--20 m alta, foliis 5--9 cm longis, 1,5--3,8 cm latis, alternis vel suboppositis, lanceolatis vel ellipticis. Floribus perfectis, apetalis. Drupis 8-12 mm longis.

Árbol o arbusto, 8-20 m de altura; ramas generalmente horizontales o escandentes, indumento de tricomas simples y diminutos. Estípulas ca. $1,5 \mathrm{~mm}$ de largo. Hojas 5-9 x 1,5-3,8 cm; alternas, subopuestas o remotamente opuestas, pecíolos 0,5-0,9 cm. Lámina foliar lanceolada a elíptica, ápice acuminado, base aguda, margen entero, con 6-9 pares de nervios secundarios a cada lado del nervio central. Inflorescencias $1-1,8 \mathrm{~cm}$ de largo, axilares y terminales, cimosas; flores con pedicelos de 2-4 mm, sépalos $5,2 \times 2 \mathrm{~mm}$, unidos en la base, valvados, triangular-ovados, internamente con 2 perforaciones separadas por un tabique de $0,2-0,4 \mathrm{~mm}$ de alto; pétalos 0 ; estambres 5, filamentos $c a .1,3 \mathrm{~mm}$, glabros, anteras ca. 0,6 mm, glabras; disco anular; ovario ca. $0,9 \mathrm{~mm}$ de diámetro; estilo 1,5 mm, bilobado. Drupas 8-12 




Figura 1. Krugiodendron acuminatum J. A. González \& Poveda. A - Ramita florida. B -Flor. C - Frutos. TeSTigo: P. Harmon 219 (INB).

$\mathrm{mm}$, subglobosas; semillas hasta de $8 \mathrm{~mm}$ de largo, sin endospermo, negras, glabras, con la superficie lisa.

Distribucion y habitat: En Costa Rica Krugiodendron acuminatum crece en los bosques costeros húmedos y estacionales del Pacífico Central y Sur, de 1-100 m de altitud, junto a especies como Licania operculipetala Standl. \& L. O. Williams (Chrysobalanaceae), Hippomane mancinella L. (Euphorbiaceae), Cynometra hemitomophylla (Donn. Sm.) Briton \& Rose (Fabaceae/Caes.), Sterculia apetala (Jacq.) H.
Karst. (Sterculiaceae), Luehea seemannii Triana \& Planch. (Tiliaceae), entre otras especies. En México crece en elestado de Veracruz, en las selvas altas perennifolias, a ca. $150 \mathrm{~m}$ de altitud.

Etimologia: El epíteto se refiere al ápice acuminado de las hojas.

Krugiodendron acuminatum se caracteriza por sus hojas glabras, alternas, remotamente opuestas o subopuestas, con los nervios terciarios finamente reticulados y conspicuos (poco evidentes en K. ferreum) y 
el ápice acuminado (siempre emarginado en $K$. ferreum). Adicionalmente, el hábito es algo escandente (completamente erecto en $K$. ferreum).

Paratipos: Costa Rica. Puntarenas: Aguirre, Quepos, Parque Nacional Manuel Antonio, 09'23'00' 'N, 84 09'00'' W, 1-100 m, 21 setiembre 1991 (fr), P. Harmon 263 (INB). MÉxico. Veracruz: Municipio Hidalgo Titlán, Río Soloxuchil, entre Hnos. Cedillo y La Escuadra, $17^{\circ} 16^{\prime} \mathrm{N}, 94^{\circ} 36^{\prime} \mathrm{W}, 150$ m, 23 agosto 1974 (fr), Vázquez V-973 (F).

Agradecimientos. Los autores desean agradecer a Michael H. Grayum, Nelson Zamora y Barry Hammel por la revisión del manuscrito, a Claudia Aragón por la ilus- tración, a Laura Torres (F) por la información brindada y especialmente a Patrick Harmon, sin cuyas recolectas e información no hubiera sido posible la publicación de la especie.

\section{Literatura Citada}

González, J. Rhamnaceae. In: B. E. Hammel, N. Zamora \& M. H. Grayum (eds.). Manual de Plantas de Costa Rica. Missouri Bot. Gard. Press, St. Louis \& Inst. Nac. de Biodiversidad, Santo Domingo de Heredia, Costa Rica. (En preparación)

Liogier, H. A. 1994. Descriptive Flora of Puerto Rico and Adjacent Islands. Vol. 3. Editorial de la Universidad de Puerto Rico. 